\title{
LEVANTAMENTO PLANORBÍDICO DO ESTADO DE SÃO PAULO: SEXTA REGIÃO ADMINISTRATIVA *
}

\author{
Jorge Faria Vaz ** \\ Horacio Manuel Santana Teles ** \\ Santa Poppe da Silva Leite ** \\ Maria Auxiliadora Corrêa ** \\ Amaury Lellis Dal Fabbro *** \\ Wandercy Santos Rosa ***
}

\begin{abstract}
VAZ, J.F. et al. Levantamento planorbídico do Estado de São Paulo: sexta Região Administrativa. Rev. Saúde públ., S.Paulo, $20: 352 \cdot 61,1986$.

RESUMO: Com o objetivo de conhecer a distribuição dos planorbídeos na sexta Região Administrativa do Estado de São Paulo, Brasil, com sede na cidade de Ribeirāo Preto, foram realizadas, durante sete meses, coletas de moluscos em ambientes hídricos de toda área. Foi verificado que os planorbídeos mais comuns no território, por ordem de frequêencia são: Drepanotrema lucidum, Biomphalaria interme. dia, Biomphalaria peregrina e Biomphalaria tenagophila. A última espécie ocorre em poucos criadouros mas vem sendo responsabilizada pela transmissão natural da esquistossomose em Bebedouro, desde 1976. B.straminea prolifera em um córrego no município de Serrana e, em uma vala, de Ribeirāo Preto. Os dados epidemiológicos e o baixo número de hospedeiros intermediários encontrados levam a crer que a possibilidade da doença disseminar-se pela regiâo é pequena.
\end{abstract}

UNITERMOS: Planorbideos. Esquistossomose, ocorrência. Epidemiologia.

\section{INTRODUÇÃO}

Os primeiros autores a estudarem a distribuição dos planorbídeos, no Estado de São Paulo, foram Coda e col.2 (1959), que procederam ao inquérito malacológico de 27 municípios e observaram a presença de hospedeiros intermediários de Schistosoma mansoni em 13 deles.

Três anos depois, Corrêa e col.6 (1962) estenderam o levantamento inicial a uma área bem maior, o que thes permitiu encontrar espécies dotadas de interesse epidemiológico em 118 dos 207 municípios investigados.

Foi somente mais tarde, em 1972, que Piza e col.10 publicaram a "Carta Planorbídica do Estado de São Paulo", documento de real valor que tem prestado grandes serviços às autoridades estaduais encarregadas do controle da esquistossomose. Com o decorrer do tempo, as informaçoes nela contidas foram perdendo atualidade. Dois principais fatores são por isso responsáveis: o lançamento de poluentes aos cursos fluviais e as alteraçбes do regime dos rios ocasionadas pela construção de barragens e de usinas hidroelétricas. Além disso, de 1972 para cá, três novas espécies de bionfalárias foram descritas e, até bem pouco tempo atrás, nada se sabia a respeito de sua distribuição pelo Estado.
Levando em consideração esses fatos, os responsáveis pela Superintendência de Controle de Endemias (SUCEN), buscando atualizar a "Carta Planorbídica" e enriquecê-la com pormenores, decidiram proceder a novo inquérito em todos os municípios paulistas o qual, iniciado em setembro de 1981, acha-se praticamente concluído.

Os resultados do levantamento levado a cabo nos ambientes dulcícolas da sexta Região Administrativa do Estado (6a R.A.), sediada na cidade de Ribeirão Preto, constituem o objeto do presente relato, e são parte de uma seqüência, iniciada em 1983, a ser oportunamente terminada.

\section{MATERIAL E MÉTODOS}

Os critérios utilizados na coleta de moluscos constam de trabalhos anteriores $13,14,15$.

As coletas foram realizadas de preferência nos peridomicílios, valas de irrigação agrícola e trechos de rios, adequados à prática de natação ou desportos aquáticos. Todos os ambientes hídricos submetidos a exame foram relacionados com as habitações que constam dos boletins de reconhe.

\footnotetext{
* Apresentado no "IX Encontro Brasileiro de Malacologia, 1985 ", Sāo Paulo.

** Do Laboratório de Malacologia da Superintendência de Controle de Endemias (SUCEN) - Rua Paula Souza, 166 - 5 P andar - 01027 - São Paulo, SP - Brasil.

** Do Serviço Regional-6 da SUCEN - Rua Minas, 877 - 14100 - Ribeirão Preto, SP - Brasil.
} 
cimento geográfico (RG) da SUCEN. Os caramujos foram remetidos, sempre com muita brevidade, ao laboratório do serviço. De cada lote foram retirados. quando possivel, 10 exemplares depositados em pequena coleção de moluscos, tomando-se, assim, viável rever, a qualquer momento e quando necessário, as determinações feitas. Para caracterização das espécies procedeu-se ao exame das partes moles em lupa binocular.

Em pesquisas anteriores visava-se descobrir pelo menos um ambiente dulcícola com caramujos, a cada $100 \mathrm{~km}^{2}$. Agora com o objetivo de conferir maior precisão ao trabalho foram evidenciados, no mínimo, dois criadouros de moluscos a cada $100 \mathrm{~km}^{2}$.

\section{CARACTERISTTICAS DA ÁREA ESTUDADA}

O território da sexta Região Administrativa abarca uma área de $36.746 \mathrm{~km}^{2}$ e abrange 80 municípios. Situa-se no extremo norte do Planal to Ocidental Paulista, grande conjunto geomorfológico constituído por extensos derrames de lavas mesozóicas entremeadas por arenitos eólicos, evidenciando discreta inclinação para a bacia do rio Paraná.

Defronta-se ao Norte e a Leste, com o Estado de Minas Gerais, separada por $260 \mathrm{~km}$ do rio Grande e pelos limites orientais de todos os municípios compreendidos entre Rifaina e Cássia dos Coqueiros (Fig. 1 e 2). A Sudeste, entra em contato com a

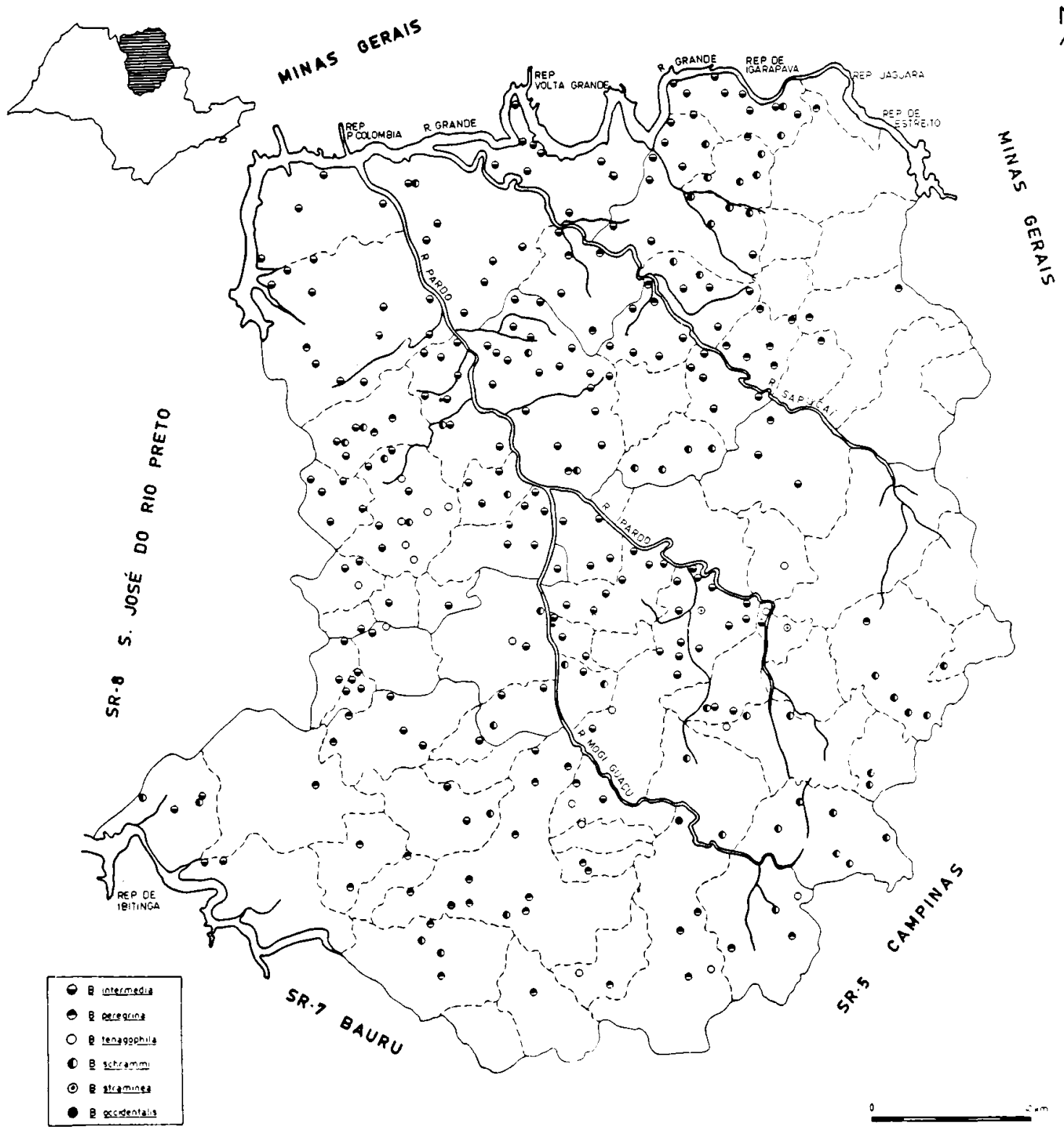

Fig. 1 - Distribuição dos criadouros de bionfalárias pela 6a Região Administrativa do Listado di São Paulo (ınarço a novembro de 1984) 


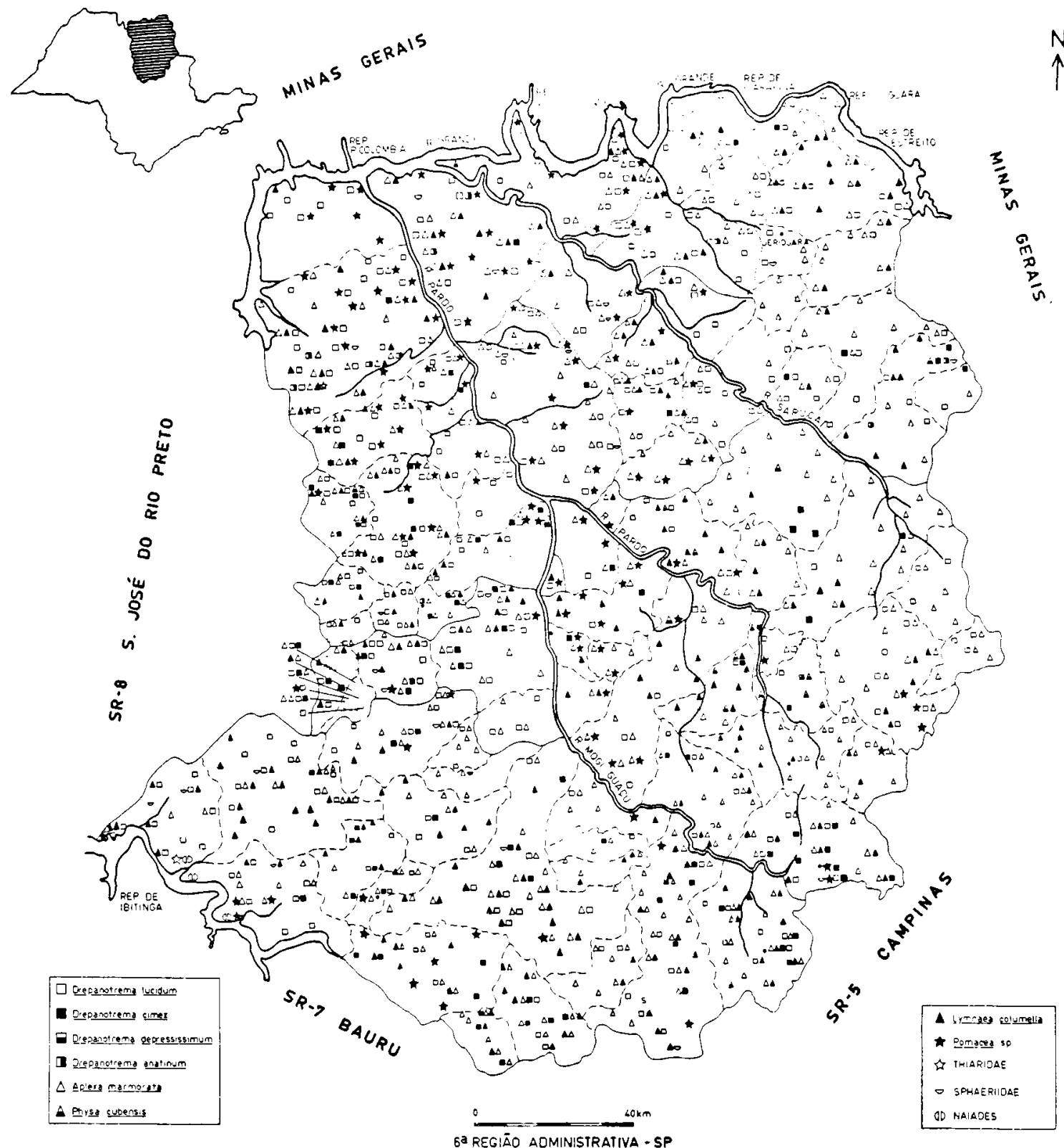

Fig. 2 - Distribuição dos criadouros de Drepanotrema, de limneídeos e de físídeos pela 6a Região Administrativa do Estado de São Paulo (março a novembro de 1984).

quinta Região e, a Sudoeste, suas fronteiras com a sétima Regiāo correspondem a $84 \mathrm{~km}$ do médio Tie tê e a $48 \mathrm{~km}$ do curso inferior do Jacaré Pepira. Os limites ocidentais dos municípios que se dispõem entre Colômbia, ao Norte e Borborema, ao Sul, separam-na da oitava Região Administrativa.

A rede hídrica regional é bastante desenvolvida e nela se destacam, além dos cursos fluviais já mencionados, os rios Sapucaí e Pardo, ambos afluentes do Grande, bem como o rio Jacaré-Guaçu, tributá- rio do Jacaré-Pepira e o Mogi-Guaçu que, nas proximidades de Viradouro, vai lançar-se no Pardo.

De um modo geral, as águas de todos os grandes cursos da Região vêm sendo consideradas ainda de boa qualidade, a julgar das informaçōes obtidas nos postos de monitoragem da Companhia de Tecnologia de Saneamento Ambiental (CETESB 3,4,5).

No "Anuário Estatístico do Estado de S.Paulo, 1983'1 encontra-se informação de que no território 
vivem 1.874 .300 pessoas sendo, no meio rural, somente 181.575 . Toda a população ocupa 410.000 habitaçōes das quais $86 \%$ são urbanas. Noventa por cento das residências das cidades são abastecidas por água. Cerca de $71 \%$ de todas as casas da área, ou seja, 292.000 acham-se ligadas à rede de esgota. mento sanitário; $27 \%$ são dotados de fossas e, por fim, cerca de $2 \%$ não dispõem de qualquer tipo de esgoto.

As atividades agrícolas acham-se amplamente voltadas para o cultivo de cana-de-açúcar que se desenvolveu a partir de 1976, com o Programa Nacional do Álcool ${ }^{7}$.

As 28 usinas de açúcar e as 16 destilarias distribuídas por toda a grande área de Ribeirão Preto, lançam hoje seus resíduos em valas superficiais abertas no solo11,12. Clandestinamente despejam o "vinhoto" em córregos e riachos os quais, extremamente poluídos, deixam de abrigar qualquer forma de vida durante largos trechos de seus cursos.

Como a cultura da cana não exige trato continuado, as lavouras são criadas e assistidas, em épocas de demanda, por mão-de-obra assalariada que reside nas áreas periurbanas. Entre os chamados "bóias. - frias", há numerosos migrantes que procedem de zonas onde a esquitossomose é endêmica. Nos útlimos dez anos 56.900 pessoas oriundas do Nordeste, da Bahia e Minas Gerais, transportaram-se de seus locais de origem para a sextá Regiẫo. Em 1982, em todo o território foram descobertos 495 casos im. portados de esquistossomose e, em 1983, mais outros 57812 .

Bebedouro, com 47.500 habitantes, é a única localidade da regiảo onde, a partir de 1976, vem sendo encontrados casos autóctones de parasitose9. Nos anos de 1982 e 1983, 20 pessoas adquiriram a doença ao se utilizarem, para fins de lazer, de um lago constituído pelo represamento do córrego Consulta12 situado no perímetro urbano. Tanto o rio como o lago recebem esgotos vindos dos domicilios próximos.

\section{RESULTADOS}

Os homens de campo da SUCEN, em curto prazo, de março a novembro de 1984, visitaram 914 localidades distribuídas pelos 80 municípios da região e, em $89 \%$ delas, encontraram moluscos que foram remetidos ao laboratório de malacologia do serviço. Houve necessidade de serem refeitas 41 das coletas iniciais, constituidas por exemplares sem vida ou jovens.

Dos 24.185 exemplares obtidos, 14.178 , ou seja, aproximadameente $58 \%$ do total procediam de águas paradas e os restantes, de ambientes hídricos com leve correnteza.

Foram coletados gastrópodos e lamelibrânquios. Entre os últimos figuram duas náiades* - Anodontites trapezialis Lamarck, 1819, representada por 28 indivíduos da represa do rio Tietê, em Borborema e Diplodon sp cujos exemplares foram obtidos de rios e córregos de Ibitinga, Matão e Miguelópolis.

Os demais pelecipodos, em número de 521, identificam-se com Pisidium sp e com Eupera sp, ambos da familia Sphaeriidae Jeffreys, 1862. Como sua determinaçâo é complexa e envolve conhecimentos especializados, os pequeninos bivalves foram incluídos no acervo do laboratório onde estão a aguardar estudos ulteriores.

Entre os prosobrânquios, Pomacea sp ioi encontrada em 40 municipios e, do gênero, foram coletados 436 exemplares. Já os "melanideos", em número de 2.305 , ocorreram somente em oito localidades e constituem motivo de comunicação à parte.

Os pulmonados dulcícolas, muito abundantes e representados por 20.950 exemplares, o que corresponde a $36,43 \%$ dos moluscos obtidos, foram identificados com as seguintes espécies:Biomphalaria intermedia (Paraense e Deslandes, 1962), Biomphalaria peregrina (d'Orbigny, 1835), Biomphalaria tenagophila (d'Orbigny, 1835), Biomphalaria schrammi (Crosse, 1864), Biomphalaria straminea (Dunker, 1848). Biomphalaria occidentalis, Paraense, 1981, Drepanotrema anatinum (d'Orbigny, 1835), Stenophysa marmorata (Guilding. 1828), Physella (Costatella) cubensis (Pfeiffer, 1839) e Lymnaea columella Say, 1817.

A freqüência relativa das diferentes espécies pode ser apreciada na Figura 3 e sua distribuição por municípios, na Tabela.

Biomphalaria intermedia, encontradiça na área, achava-se presente em 171 dos biótopos examina. dos. A maioria de scus criadouros ocorre nos munjcípios ocidentais e ao norte, sendo sua densidade mais elevada em Jaborandi, Barrinha, Aramina, Monte Azul Paulista, Sertãozinho e Igarapava. $B$ intermedia e os demais representantes do gênero não ocorrem nos seguintes municípios situados a leste da Região, os quais perfazem $4.025 \mathrm{~km}^{2}$ : Rifaina, Pedregulho, Cristais Paulista. Franca, Patrocínio Paulista, Itirapuã, Altinópolis, Santo Antônio da Alegria e Cássia dos Coqueiros. Deixa também de comparecer em mais 26 municípios, ao centro e ao sul do território.

\footnotetext{
* Designação aplicada aos bivalves das famílias Unionidae e Hyriidae sensu Parodiz \& Bonetto, 1963.
} 
VAZ, J.F. et al. Levantamento planorbídico do Estado de São Paulo: sexta Região Administrativa. Rev. Saúde públ., S.Paulo, 20: 35 2-61, 1986.

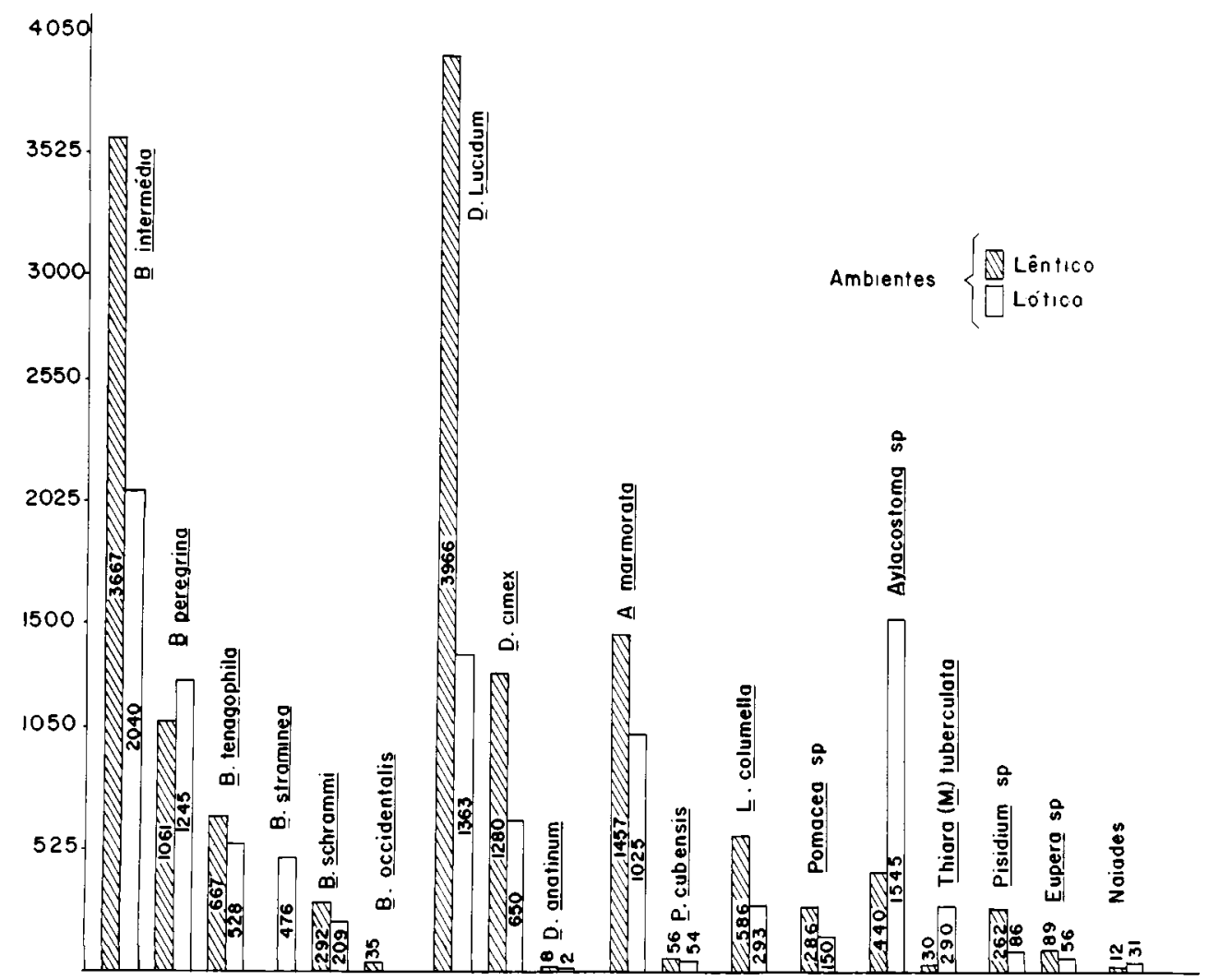

Fig. 3 Moluscos dulcícolas da 6a Região Administrativa do Lstado de São Paulo (dados quantitativos).

Biomphalaria peregrina coloniza 44 ambientes hídricos irregularmente distribuidos pelo território. E mais comum em São José da Bela Vista, Américo Brasiliense, Nova Europa, Pradópolis, Ipuã e Araraquara. Em Altinópolis, com $943 \mathrm{~km}^{2}$, há um único criadouro da espécie. Os demais criadouros de moluscos do município não abrigam bionfalárias.

Biomphalaria tenagophila, embora pouco comum, foi encontrada em 14 municípios. Proliferava em 20 biótopos dos quais, 6 situados na bacia do Mogi-Guaçu (Descalvado, Ibaté, Jaboticabal, Rincão, Santa Lúcia e São Carlos), 12 em localidades relacionadas com tributários do rio Pardo (Bebedouro, Brodosqui, Colina, Ribeirão Preto, São Simão e Serrana) e dois em municípios cujos rios vão desaguar no Turvo (Monte Alto e Pirangi).

Não foi possível confirmar a presença de B. tenagophila em 4 municípios assinalados por Piza e col. 10 em sua "Carta Planorbídica" que são - Araraquara, Guará, Ibitinga e Ituverava.
Os 4 biótopos que abrigam a espécie, em Bebe. douro, acham-se dentro do perímetro urbano e o mesmo acontece em Monte Alto, Ribeirão Preto e Pirangi. Na cidade de Bebedouro, no lago Municipal, B. tenagophila vive simpatricamente com B. schrammi. $\mathrm{Na}$ mesma coleção hídrica foram coletados representantes de Drepanotrema lucidum, Stenophysa marmorata e Pomacea sp.

Documentos da SUCEN comprovam que a 20 de abril de 1976 alguns dos exemplares do lago estavam a eliminar cercárias de S.mansoni, fato que despertou a atenção de sanitaristas para o problema. Pesquisas feitas ulteriormente pela SUCEN deixaram de evidenciar a presença de caramujos infectados na represa.

Em Jaboticabal, nas imediações do centro urbano, B. tenagophila constitui população de baixa densidade em valas de horta da Escola Agrícola da Universidade Estadual de São Paulo. 
VAZ, J.F. et al. Levantamento planorbídico do Estado de São Paulo: sexta Região Administrativa. Rev.Saúde públ., S.Paulo, 20:352-61, 1986.

\section{TABELA}

Distribuição dos moluscos dulcísolas por municípios - 6a Região Administrativa - SP.

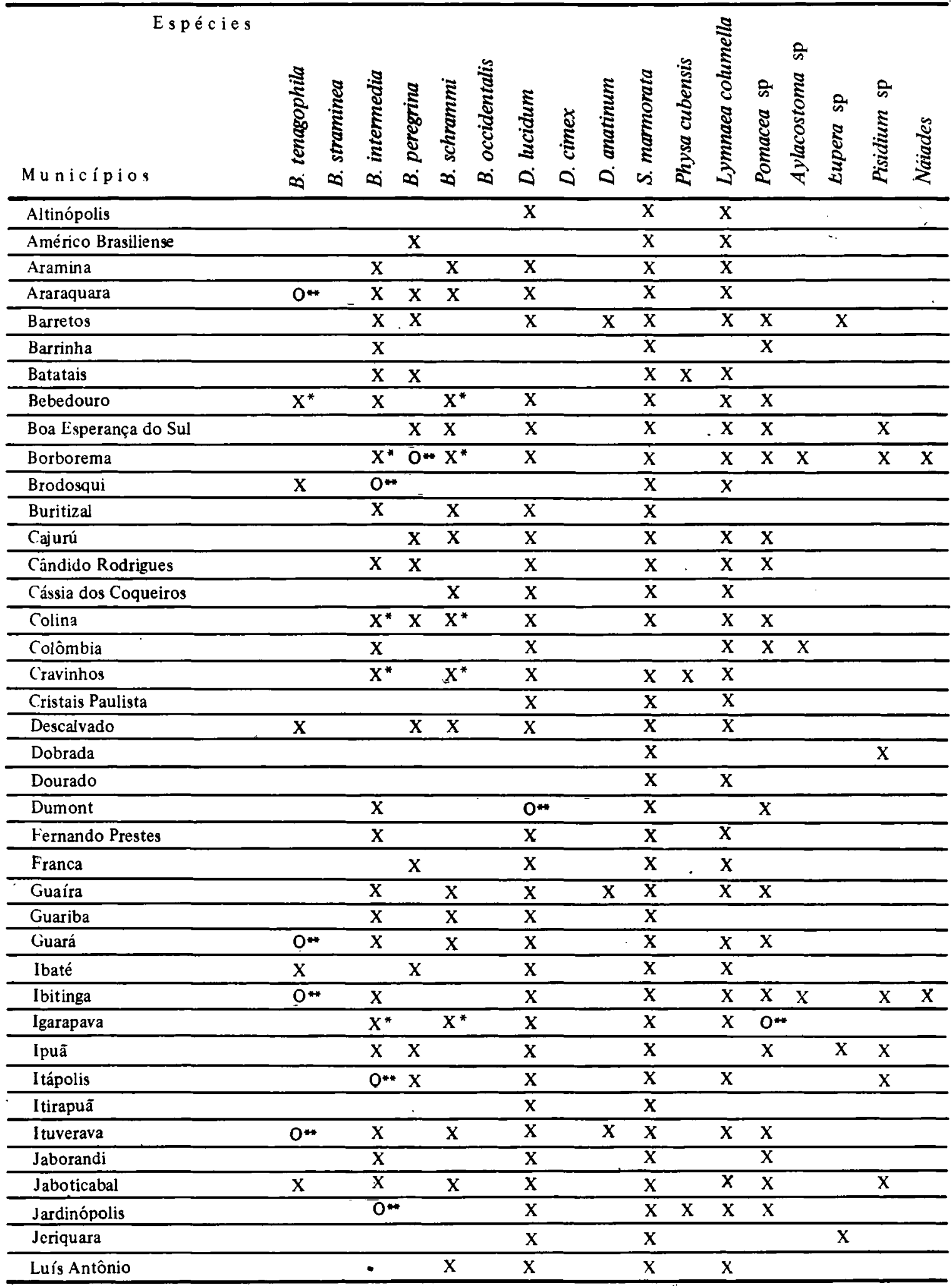


VAZ, J.F. et al. Levantamento planorbídico do Estado de São Paulo: sexta Regiāo Administrativa. Rev.Saúde públ., S.Paulo, 20 : 35 2-61, 1986.

continuação

\begin{tabular}{|c|c|c|c|c|c|c|c|c|c|c|c|c|c|c|c|c|c|}
\hline Municípios & 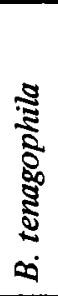 & 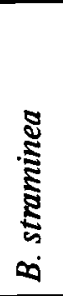 & 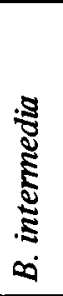 & 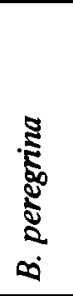 & 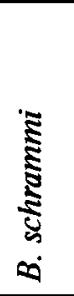 & 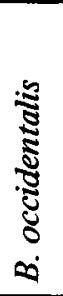 & 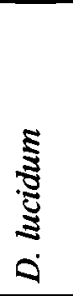 & 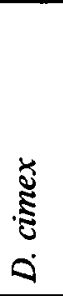 & 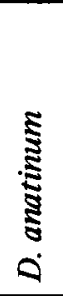 & 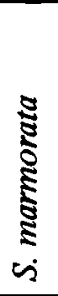 & 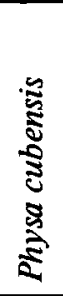 & 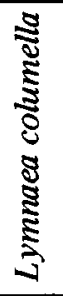 & 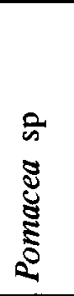 & 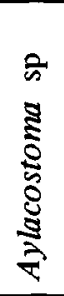 & $\begin{array}{l}\text { क } \\
\text { s } \\
\vdots \\
\vdots \\
5\end{array}$ & 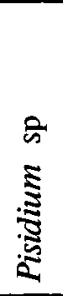 & 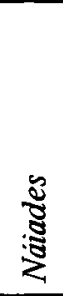 \\
\hline Matão & & & $X$ & & $\mathrm{X}$ & & $\mathrm{X}$ & & & $X$ & & $\mathbf{X}$ & & & & & $\mathrm{X}$ \\
\hline Miguelópolis & & & $\mathrm{X}$ & & & & $\mathrm{X}$ & & & $\mathrm{X}$ & $\mathrm{X}$ & $\mathrm{X}$ & $\mathrm{X}$ & $\mathrm{X}$ & & & $\mathrm{X}$ \\
\hline Monte Alto & $\mathrm{X}$ & & $\mathrm{X}$ & & & & $\mathrm{X}$ & & & $\mathrm{X}$ & & $\mathrm{X}$ & $\mathrm{x}$ & & & $\mathrm{X}$ & \\
\hline Monte Azul Paulista & & & $\mathrm{X}$ & & & & $\mathrm{X}$ & & & $\mathrm{X}$ & & $\mathrm{X}$ & $\mathrm{X}$ & & & $\mathrm{X}$ & \\
\hline Morro Agudo & & & $\mathrm{X}$ & $\mathrm{X}^{*}$ & $\mathrm{X}^{*}$ & & $\mathrm{X}$ & & & $\mathrm{X}$ & & $\mathrm{X}$ & $\mathrm{X}$ & & $\mathrm{X}$ & & \\
\hline Nova Europa & & & & $\mathrm{X}$ & $\mathrm{O}^{* *}$ & & $\bar{X}$ & & & $\mathrm{X}$ & & $\mathbf{X}$ & $\mathrm{X}$ & & & & \\
\hline Nuporanga & & & $\mathrm{X}$ & & & & $\mathrm{X}$ & & & $\bar{x}$ & & & $\mathrm{X}$ & & & & \\
\hline Orlândia & & & & & & & $\mathbf{X}$ & & & $\mathbf{X}$ & & $\mathrm{X}$ & $\mathrm{X}$ & & & $\mathrm{X}$ & \\
\hline Patrocínio Paulista & & & & & & & $x$ & & $\bar{X}$ & $\bar{X}$ & $\mathrm{X}$ & $\mathrm{X}$ & & & $\mathrm{X}$ & & \\
\hline Pedregulho & & & & $\mathrm{X}$ & & & $\mathrm{X}$ & & & $\mathrm{X}$ & $\mathrm{X}$ & $\mathrm{X}$ & & $\mathrm{X}$ & & & \\
\hline Pirangi & $\bar{X}$ & & $\mathrm{X}$ & & & & $\mathrm{X}$ & & & $\mathrm{X}$ & & $\mathrm{x}$ & $O^{* *}$ & & & & \\
\hline Pitangueiras & & & $\mathrm{X}$ & & & & $\mathbf{X}$ & & & $\mathrm{X}$ & & $\mathrm{X}$ & $\mathrm{X}$ & & & & \\
\hline Pontal & & & $\bar{X}$ & & O** & & $\mathrm{X}$ & & & $\mathrm{X}$ & & $\mathrm{X}$ & $\mathrm{X}$ & & & & \\
\hline Pradópolis & & & $\mathrm{X}$ & $\mathrm{X}^{*}$ & $\mathrm{X}^{*}$ & & $\mathrm{X}$ & & & $\bar{x}$ & & $\mathrm{X}$ & $\mathrm{X}$ & & $\mathrm{X}$ & & \\
\hline Restinga & & & & $\mathrm{X}$ & & & $\mathrm{X}$ & & & $\mathrm{X}$ & & $\mathrm{X}$ & & & & & \\
\hline Ribeirão Bonito & & $\bar{x}$ & & $\mathrm{X}$ & $\mathrm{O}^{* *}$ & & $\mathrm{X}$ & & & $\bar{X}$ & & $\bar{X}$ & & & & & \\
\hline Ribeirão Corrente & & & & & & & & & & $\mathrm{X}$ & & & & & & & \\
\hline Ribeirão Preto & $\mathrm{X}$ & $\mathrm{X}$ & $\mathrm{X}$ & $0 * *$ & & & $\mathrm{X}$ & & & $\mathrm{X}$ & $\mathrm{X}$ & $\mathrm{X}$ & $\mathrm{X}$ & & & & \\
\hline Rifaina & & & & & & & & & & $\mathrm{X}$ & & & & $\mathrm{X}$ & & & \\
\hline Rincāo & $\mathrm{X}$ & . & & $\mathrm{X}$ & & & $\mathrm{X}$ & & & $\bar{X}$ & & $\bar{X}$ & $\mathrm{X}$ & & & $\mathrm{X}$ & \\
\hline Sales Oliveira & & & $\mathrm{O}^{* *}$ & & $\mathrm{X}$ & & & & & $\mathrm{X}$ & & $\bar{X}$ & $\mathrm{X}$ & & & & \\
\hline Santa Emestina & & & $\mathrm{X}$ & & & & $\mathrm{X}$ & & & $\mathrm{X}$ & & & & & & & \\
\hline Santa Lúcia & $\mathrm{X}$ & & $\mathrm{O}^{* * 4}$ & & & & $\mathrm{X}$ & & & $\mathrm{X}$ & & & & & & & \\
\hline Santa Rita do Passa Quatro & & & & & $\mathrm{X}$ & & $\mathrm{X}$ & & & $\mathrm{X}$ & & $\mathrm{X}$ & $\mathrm{X}$ & & $\mathrm{X}$ & & \\
\hline Santa Rosa do Viterbo & & & & & $\mathrm{X}$ & & $\mathrm{X}$ & & & $\mathrm{X}$ & & $\mathrm{X}$ & $\mathrm{X}$ & & & & \\
\hline Santo Antônio da Alegria & & & & & & & $\mathrm{X}$ & & & $\mathrm{x}$ & & & & & & & \\
\hline São Carlos & $\mathrm{x}$ & & & $\mathrm{X}$ & & $\mathrm{X}$ & $\mathrm{X}$ & & & $\bar{x}$ & & $\bar{X}$ & $\mathrm{X}$ & & $\mathrm{X}$ & $\mathrm{X}$ & \\
\hline São Joaquim da Barra & & & $\mathrm{X}$ & $\mathrm{X}$ & & & $\mathrm{X}$ & & & $\mathrm{X}$ & & $\mathrm{X}$ & $\mathrm{X}$ & & & & \\
\hline São José da Bela Vista & & & & $\mathrm{X}$ & & & $\mathrm{X}$ & & & $\mathrm{X}$ & & & & & & & \\
\hline Sāo Simão & $\mathrm{X}$ & & & & $\mathrm{X}$ & & $\mathrm{X}$ & & & $\mathrm{X}$ & & $\mathrm{x}$ & & & & & \\
\hline Serra Azul & & & & & & & $\mathrm{X}$ & & & & $\mathrm{X}$ & & & & & & \\
\hline Serrana & $x$ & $\mathbf{X}$ & $\mathrm{x}$ & & & & $\mathrm{X}$ & & & $\mathrm{X}$ & $\mathrm{X}$ & $\mathrm{X}$ & $\mathrm{X}$ & & & & \\
\hline Sertãozinho & & & $\mathrm{X}$ & & & & $\bar{X}$ & & & $\mathrm{X}$ & & $\mathrm{X}$ & $\mathrm{X}$ & & & & \\
\hline Tabatinga & & & & $\mathrm{X}$ & & & $\mathrm{X}$ & & & $\mathbf{X}$ & & $\mathrm{X}$ & & & & & \\
\hline Taiaçu & & & $\mathrm{X}$ & & & & $\mathrm{X}$ & & & $\mathrm{X}$ & & $\mathrm{X}$ & & & & $\mathrm{x}$ & \\
\hline Taiuva & & & $\mathrm{X}$ & & & & $\mathrm{O}^{* *}$ & & $\mathrm{X}$ & $\bar{X}$ & & $\mathrm{X}$ & $\mathrm{X}$ & & & & \\
\hline Taquaritinga & & & $\mathrm{X}$ & $\mathrm{X}$ & & & $\mathrm{X}$ & & & $\mathrm{X}$ & & $\mathrm{X}$ & & & & $\mathrm{X}$ & \\
\hline Terra Roxa & & & $\mathrm{X}^{*}$ & & $\mathrm{X}^{*}$ & & $\mathrm{X}$ & & & $\mathrm{X}$ & & $\mathrm{X}$ & $\bar{X}$ & & & & \\
\hline Viradouro & & & $\mathrm{X}$ & & $\mathrm{X}$ & & $\mathrm{X}$ & & & & & & $\mathrm{x}$ & & & & \\
\hline Vista Alegre do Alto & & & $\mathrm{X}$ & & $\mathrm{O}^{* *}$ & & $\mathrm{X}$ & & & $\mathrm{X}$ & & $\mathrm{X}$ & & & & & \\
\hline$T O T A L$ & 13 & 02 & 45 & 25 & 27 & 01 & 69 & 05 & 09 & 77 & 09 & 62 & 40 & 07 & 08 & 14 & 04 \\
\hline
\end{tabular}


VAZ, J.F. et al. Levantamento planorbídico do Estado de São Paulo: sexta Regiāo Administrativa. Rev.Saúde públ., S.Paulo, 20: 352-61, 1986.

A metodologia empregada só permitiu encontrar 20 biótopos com B.tenagophila em toda a região. Outros nas mesmas condições escaparam, com certeza, à pesquisa. Em Bebedouro, por exemplo, buscas exaustivas, após a conclusão do inquérito, mostraram que lá existem na realidade 19 criadouros da bionfalária e não somente os quatro agora considerados.

Biomphalaria straminea foi encontrada em dois municípios. Em Serrana vivia en tanques de criação de peixes da fazenda Lázaro Neto, hoje desativados. Anos atrás, após inundação da área, devida a chuvas copiosas, passou a colonizar o córrego Serrana que, vindo de Serra Azul, passa junto ao centro urbano para depois lançar-se no Pardo. Dois quilômetros antes da confluência, o curso d'água recebe os resíduos de várias usinas de açúcar. Entre esse ponto e a fazenda, é possivel encontrar junto às margens, alguns exemplares da espécie mas, no trecho poluído, não existe um só caramujo vivo. Em Ribeirão Preto ocorre em viveiro de plantas aquáticas de uma chácara, próxima à via férrea, na esquina da rua Dois com a Quatro. A água dos tanques, onde ela se encontra, vai ter a uma vala que termina no rio Pardo. Pesquisas realizadas no próprio rio não evidenciaram a presença do caramujo em questão.

Biomphalaria schrammi prolifera isoladamente em 20 municípios. Como já foi dito, vive em Bebedouro em simpatria com B.tenagophila; ocorre junto com B. intermedia em quatro localidades e, em companhia de B.peregrina, em um criadouro de Pradópolis.

Biomphalaria occidentalis coloniza um córrego sinuoso em São Carlos e, de um de seus meandros. foram obtidos 7 exemplares.

Os ambientes hídricos que abrigam as bionfalárias já referidas, acham-se assinalados na Figura 1 .

Drepanotrema lucidum é o representante do gènero mais comum em toda a área. Distribui-se por 69 municípios e dele foram coletados 5.329 exemplares que procediam de 380 biótopos dos quais 100 eram lóticos.

Drepanotrema cimex é menos frequente na r'gião e se encontra presente em 44 municípios.

Drepanotrema anatinum, por sua vez, distribui-se unicamente por 5 municípios. Ocorre em 10 criadouros dos quais 8 , do tipo lêntico.

Lymnaea columella, Physella cubensis e Stenophysa marmorata convivem com todas as demais espécies e se encontram amplamente distribuídas pela região. S.marmorata é abundante e só não foi encontrada em 3 dos 80 municípios da Região.

A distribuição dos criadouros de limneídeos e de fisídeos, bem como a dos representantes do gênero Drepanotrema pelos municípios da área submetida a exame, pode ser observada na Figura 2.

\section{COMENTÁRIOS}

Para os limnólogos, e também para os sanitaristas, é de importância o conhecimento da distribuição dos bivalves dulcícolas. Esses moluscos fazem parte de um grupo de organismos constituidos por representantes de vários filos que, em conjunto, podem ser utilizados como indicadores biológicos da qualidade das águas. No Estado de São Paulo, Johnscher e col. 8 valeram-se de um método, em que figuram os bivalves, para estudar as águas do largo trecho do rio Atibaia. No decorrer do presente inquérito foram encontrados numerosos esferídeos, que toleram bem a poluição orgânica e, raras náiades, mais sensiveis às modificaçoes do ambiente.

Com relação aos planorbídeos, os resultados mostram que o mais comum em toda a região é Drepanotrema lucidum, encontrado em 69 municípios. Ele prolifera nos mais diversos biótopos, isoladamente ou em simpatria com outros representantes da família.

A segunda espécie mais frequente é Biomphalaria intermedia que embora ocorra em 171 criadouros, deixa de comparecer não só nos municípios mais orientais da região, fronteiriços com Minas, mas também em vários outros situados ao centro e ao sul do território. No momento é difícil explicar essa distribuição, pois os conhecimentos até agora acumulados sobre a biologia dos planorbídeos provêm quase que exclusivamente de experimentos de laboratório e pouco se aplicam ao campo. Raros pesquisadores tiveram a preocupação de estudar a influência dos diferentes parâmetros ambientais ou dos fatores limitantes sobre o desenvolvimento das populações naturais de caramujos.

Ainda que no momento fosse possível dispor de informações completas sobre os ambientes hídricos, situados a leste, sua importância sobre a dinâmica populacional dos basomatóforos superiores não poderia ser devidamente aquilatada por falta de pesquisa básica sobre o assunto.

Ao que tudo indica, Biomphalaria straminea, que prospera em dois riachos - um situado em Serrana e outro em Ribeirão Preto, dificilmente conseguirá expandir-se pelo território porque, na primeira localidade perece ao entrar em contato com os resíduos das usinas açucareiras e, no segundo, deixa de ser en. contrada no rio Pardo, onde as condições ambientais lhe são adversas.

Também Biomphalaria tenagophila não encontra ambientes favoráveis a sua dispersão. Caso contrário, seus criadouros seriam mais numerosos. 
VAZ, J.F. et al. Levantamento planorbídico do Estado de São Paulo: sexta Região Administrativa. Rev.Saúde públ., S.Paulo, 20: 35 2-61, 1986.

Em Bebedouro, como já foi mencionado, a relação entre o número de criadouros de B.tenagophila, evidenciados pela pesquisa, e o número de biótopos que abrigam o caramujo, equivale aproximadamente a $1 / 5$. Sabendo que em toda a região foram encontrados 20 ambientes hidricos com B.tenagophila, e admitindo que a proporção anterior seja válida para o território, é possível estimar, em uma centena, o número de criadouros da espécie que ocorrem em toda a área. A grande maioria deles fica situada na zona rural onde seus exemplares deveriam encontrar-se mais expostos à infecção por S.mansoni.

Dados estatísticos, já referidos, mostram que 10.700 habitações no campo e regiões periurbanas não dispõem de qualquer tipo de fossa ou de esgoto ${ }^{10}$. Ora, cada residência abriga, em média, quatro e cinco moradores conforme é possivel deduzir de cifras já anteriormente mencionadas. Em conseqüência, cerca de 48.150 pessoas, mesmo que se utilizem de latrinas, eliminam seus dejetos nas proximidades de riachos, de córregos e também sob vegetações de certo porte, contaminando o lençol freático superficial, as coleções hídricas e os meios lóticos. A esse número deve ser acrescentado o dos trabalhadores rurais que abrange boa parte dos migrantes procedentes de zonas onde a esquistossomose é endêmica. No entanto, é preciso lembrar que os resíduos das usinas de açúcar e das distilarias normalmente são lançados em sulcos cavados no solo e vão comprometer a vitalidade das larvas e dos ovos eliminados com as fezes.

Ante o exposto, a infeç̧ão dos caramujos na zona rural da sexta região, se é que existe, deve ser considerada pouco freqüente.
Já no chamado lago Municipal de Bebedouro, situado no perímetro urbano, tudo favorece o desenvolvimento dó. ciclo natural de transmissão de S.mansoni. Ao córrego Consulta, e ao proprio lago, vão ter os esgotos das casas próximas; a população freqüenta a pequena represa para fins de lazer e, nela, B.tenagophila encontra condições propícias a seu desenvolvimento. Passos e col.9, em 1976, descobriram os primeiros casos autóctones de esquistossomose na cidade relacionando-os com o lago.

A proposta de aterrá-lo e de construir piscinas públicas na mesma área, feita há alguns anos atrás* foi mal recebida pela população. Resta, asim, levar os esgotos até uma lagoa de oxidação. A medida seria de efeito temporário porquanto é de se presumir que novas ligações clandestinas de esgotos possam ser feitas, após certo tempo, desde que não haja fiscalização e fetiva.

\section{CONCLUSÕES}

1. Biomphalaria straminea prolifera livremente em duas localidades da Região e parece não dispor de condições favoráveis à dispersão pela área examinada.

2. Biomphalaria tenagophila, embora pouco freqüente, é responsável pela transmissão da esquistossomose em Bebedouro, desde $1976 \mathrm{e}$, ao que tudo indica, encontra dificuldade para dispersarse pelo território.

3. O baixo número de hospedeiros intermediários e os dados epidemiológicos sugerem que a esquistossomose não tenha possibilidade de disseminarse pela região.

VAZ, J.F. et al. [ Planorbidic survey of the $6^{\text {th }}$ Administrative Region of the State of S.Paulo, Brazil ] .

Rev.Saúde públ., S.Paulo, $20: 35$ 2-61, 1986.

ABSTRACT: A systematic survey was carried out in the area of the $6^{\text {th }}$ Administrative Region of the State of S.Paulo, in order to discover the distributional patterns of planorbidic snails. Biomphalaria tenagophila is incriminated as the intermediary of Schistosoma mansoni in Bebedouro county where some human cases of the disease have been observed since 1976. Biomphalaria straminea lives at two breeding places - in Serrana and Ribeirão Preto. It is concluded that there is little possibility of schistosomiasis spreading in the studied area.

UNITERMS: Planorbidae. Schistosomiasis, occurrence. Epidemiology.

\section{REFERẼNCIAS BIBLIOGRÁFICAS}

1. ANUÁRIO ESTATISTICO DO ESTADO DE SÃO PAULO: 1983. (Fundação SEADE). São Paulo. 1984.

2. CODA, D.; FALCI, N. \& MENDES, F.A.T. Contribuição para o estudo e profilaxia da esquistossomose no Estado de São Paulo. Rev.Inst.Adolfo Lutz, 19 : $25 \cdot 68,1959$.
3. COMPANHIA DE TECNOLOGIA DE SANEAMENTO AMBIENTAL (CETESB). Qualidade das aguas interiores do Estado de São Paulo. São Paulo, 1978.

4. COMPANHIA DE TECNOLOGIA DE SANEAMENTO AMBIENTAL (CETESB). Qualidade das águas interiores do Estado de São Paulo. São Paulo, 1980.

\footnotetext{
* Comunicação pessoal do Dr. José de Toledo Piza, então Superintendente da Campanha de Combate à Esquistossomose (CACESQ).
} 
5. COMPANHIA DE TECNOLOGIA DE SANEAMENTO AMBIENTAL (CETESB). Qualidade das águas inte. res do Estado de Sāo Paulo. São Paulo, 1983.

6. CORREA, R.R.; PIZA, J.T.; RAMOS, A.S. \& CA. MARGO, L.V. de Planorbídeos do Estado de São Paulo: sua relação com a esquistossomose (Pulmonata - Planorbidae). Arq.Hig., S.Paulo, 27 (92) : 139-59, 1962.

7. FUNDAÇÃO SEADE. A regiāo de Ribeirão Preto: um novo polo de atraçāo migratória? São Paulo, 1982. (Análise Demográfica R zgional, 7).

8. JOHNSCHLR, G.J. A comunidade bentônica $e$ a caracterizaçấo da qualidade da água de um trecho do rio Atihaia. São Paulo, CETESB, 1979. (Publ. n! 27).

9. PASSOS, A.D.C.; CARVALHEIRO, J.R.; GOMES, U.A.; KIMURA, E.T.; SILVA, G.F.; SATO, H.T.; BETTIOL, H.; MAIMONE, J.M.C.; VILARES, S.A. UEMURA, L.; ALVES, L.N.R. \& MARTINS, M.D. Descrição de um novo foco endêmico de esquistossomose mansônica no Estado de São Paulo, Brasil. Rev.Saúde públ., S.Paulo, 13: 341-7, 1979.

10. PIZA, J. de T.; RAMOS, A. da S.; MORAES, L.V.C. de; CORREA, R. de R.; TAKAKU, L. \& PINTO, A.C. de M. Carta planorbidica do Estado de Sāo Paulo. São Paulo, Secretaria de Estado da Saúde, s.d.
11. SUPERINTENDENCIA DE CONTROLE DE ENDEMIAS (SUCEN). Anteprojeto de controle de artrópodes incômodos e nocivos do Estado de Sâo Paulo. São Paulo, s.d. [ Mimeografado].

12. SUPERINTENDENCIA DE CONTROLE DE ENDEMIAS (SUCEN). Programa de controle da esquistossomose mansônica no Estado de São Paulo. São Paulo, 1984. [ Mimeografado $]$.

13. VAZ, J.F.; ELMOR, M.R.D.: GONÇALVES, L.M.C. \& iSHIHATA, G.K. Resultados do levantamento planorbídico na área de Presidente Prudente, São Paulo. Rev.Inst.Med.trop. S. Paulo, $25: 120-6,1983$. 1983.

14. VAZ, J.F.; ELMOR, M.R.D. \& GONÇALVES, L.M.C. Levantamento planorbídico do Estado de São Paulo - 8a Região Administrativa. Bol.Zool.USP, 1987 ? [ no prelo.].

15. VAZ, J.F.; ELMOR, M.R.D. \& GONÇALVES, L.M.C. Levantamento planorbídico do Estado de São Paulo = 9ạ Região Administrativa. Bol.Zool.USP, 1987 ? [ no prelo $]$

Recebido para publicaçāo em 13/12/1985.

Reapresentado em 31/07/1986

Aprovado para publicaçāo em 06/08/1986 